ORIGINAL ARTICLE

\title{
Reported versus confirmed wheeze and lung function in early life
}

\author{
L Lowe, C S Murray, L Martin, J Deas, E Cashin, G Poletti, A Simpson, A Woodcock, A Custovic
}

Arch Dis Child 2004;89:540-543. doi: 10.1136/adc.2003.038539

See end of article for authors' affiliations

Correspondence to: Mrs L Lowe, North West Lung Research Centre, Wythenshawe Hospital, Manchester M23 9LT, UK; llowe@fs1.with.man.ac.uk

Accepted 10 October 2003

\begin{abstract}
Aims: To investigate the relation between parentally reported wheeze (unconfirmed), physician confirmed wheeze, and subsequent lung function.

Methods: Children at risk of allergic disease (one parent atopic) were recruited antenatally and followed prospectively from birth. During the first three years of life parents were asked to contact the study team if their child was wheezy. The presence of wheeze was confirmed or not by the primary care or study physician. Respiratory questionnaire and specific airway resistance measurement (sR $\mathrm{aw}_{\text {, body }}$ plethysmograph) were completed at age 3 years.

Results: A total of 454 children were followed from birth to 3 years of age. One hundred and eighty six $(40.9 \%)$ of the parents reported their child wheezing in the first three years of life, and in $130(28.6 \%)$ the wheeze was confirmed. A total of 428 children attended the three year clinic review, of whom $274(64 \%)$ successfully carried out lung function tests. There was no significant difference in $\mathrm{sR}_{\mathrm{aw}}(\mathrm{kPa} \cdot \mathrm{s} ;$ geometric mean, 95\% Cl) between children who had never wheezed ( $n=152 ; 1.03,1.00$ to 1.06 ) and those with a parentally reported but unconfirmed wheeze $(n=36 ; 1.02,0.96$ to $1.07, p=1.00)$. s $R_{a w}$ was significantly higher in children with a physician confirmed wheeze $(n=86 ; 1.17,1.11$ to $1.22, p<0.001)$ compared to those with no history of wheeze or with unconfirmed wheeze.

Conclusions: Children with physician confirmed wheeze have significantly poorer lung function compared to those with parentally reported but unconfirmed and those who have never wheezed. A proportion of parents may have little understanding of what medical professionals mean by the term "wheeze".
\end{abstract}

$\mathrm{T}$ here is little doubt that the prevalence of asthma and reported wheezing has risen substantially over recent decades. ${ }^{1-3}$ Lung function tests are routinely used in adults and older children to aid diagnosis, monitor disease progression, and evaluate therapeutic interventions.

Lung function requiring forced manoeuvres is a difficult and time consuming procedure to perform in preschool children, particularly in those under 4 years of age. As a result, the diagnosis of asthma and estimates of prevalence of wheeze in young children are primarily based on parental reporting of symptoms. Several authors have suggested that dynamic lung volumes can be reliably measured in preschool children using conventional spirometry. ${ }^{4-7}$ However, all of these studies used subjects aged between 3 and 6 years, with few children at the younger end of the age range. For example, although the age range of participants in a study by Eigen et al was 36-87 months, the mean age was 59.7 months. ${ }^{4}$ Vilozni et al recruited 112 children; only nine of those tested were between 3 and 4 years of age. ${ }^{5}$ Taking into account the number of refusals, which is an important consideration when assessing the usefulness of any paediatric lung function technique, the success rate appears to be only $38.4 \% .{ }^{5}$ Crenesse et al studied 355 patients; less than $10 \%$ of the 3-4 year old children were able to perform three acceptable manoeuvres. ${ }^{6}$ In a study by Nystad et al of 652 subjects, less than $40 \%$ could perform three acceptable $\mathrm{FEV}_{1}$ manoeuvres, with younger children being less likely to be able to perform the test adequately. ${ }^{7}$

During recent years, this problem has been in part overcome by adapting plethysmographic measurement of specific airway resistance $\left(s R_{a w}\right)$ for use in young children from the age of 2 years. ${ }^{8} 9 \mathrm{SR}_{\mathrm{aw}}$ is a measure of airway calibre with airway narrowing resulting in increased values. We recently reported that $\mathrm{sR}_{\mathrm{aw}}$ measurement by plethysmography can be successfully performed in the majority of children
(64\%) within a few weeks of their third birthday. ${ }^{10} \mathrm{sR}_{\mathrm{aw}}$ was significantly increased in children with recurrent wheeze compared with those with little or no history of wheeze, confirming the validity of the technique.

Several studies have reported that parents often confuse wheeze with other respiratory sounds, which may lead to under or overestimation of the true prevalence of wheeze and perhaps overtreatment. ${ }^{11}{ }^{12}$ The possible responder bias in subjectively reported symptoms emphasises the need for objective outcomes. We aimed to compare an objective measure of lung function in children with parentally reported but unconfirmed wheeze and those with a physician confirmed wheeze.

\section{METHODS}

Study population

${ }^{\mathrm{NAC}}$ MAAS is a prospective cohort study, described in detail elsewhere. ${ }^{13}$ Briefly, more than 1000 subjects were recruited in utero (8-10th week of pregnancy) by screening parents in the antenatal clinic using skin testing and a questionnaire regarding allergic diseases. ${ }^{14}$ We report here on 525 children at higher risk of allergic disease (one atopic parent) who formed the recruitment basis for the nested randomised study of the secondary prevention of asthma by the use of early treatment (as described in detail previously). ${ }^{14}$ The study had the approval of the local research ethics committee.

\section{Study protocol}

During the first three years of life, the study team contacted parents by telephone every three months to check on the health of the child. In addition, parents were asked to contact the study team immediately if their child wheezed. If parents reported that their child had wheezed, they were asked to visit their general practitioner (GP) immediately for verification. If they were unable to attend the GP's surgery, a 
member of the study team would visit the child in their home on the same day to confirm that the child was wheezing.

All subjects were invited to a review clinic at 3 years of age (within four weeks of birthday) to perform $\mathrm{sR}_{\mathrm{aw}}$ measurements. The children were classified as follows:

- Never wheezed (no parental or physician reported wheeze)

- Unconfirmed wheeze (parentally reported wheeze not confirmed by the GP or study physician on examination)

- Confirmed wheeze (parentally reported wheeze confirmed by physician examination).

\section{Lung function}

All children were asymptomatic at the time of the lung function assessment and were asked to refrain from $\beta_{2}$ agonist use for at least four hours before their appointment. $s R_{a w}$ was measured by a single step procedure from the simultaneously measured changes of respiratory flow and changes of plethysmographic pressure, omitting the measurement of thoracic gas volume. ${ }^{15}$ Measurements were carried out during tidal breathing using a modified facemask (Astratech no. 2; Astra Denmark). ${ }^{8}$ The procedure was explained to the parent and the use of the facemask was demonstrated to the child. It was explained to the child that a video would start when they breathed through the mask. Children were encouraged to sit in the plethysmograph cabinet alone, but if they refused, the parent was asked to sit in the plethysmograph with the child on their knee. ${ }^{8}$ The door of the plethysmograph was closed and the subject asked to breathe through the facemask. The spirometry trace was observed and the child was encouraged to breathe at a respiratory rate of $30-45$ breaths/min. If the child was accompanied the parent was asked to inhale and hold their breath for approximately 20 seconds. When the specific resistance loops returned to a normal shape after this manoeuvre and the spirometry trace was stable, $s R_{a w}$ was calculated from the median of five technically acceptable loops. Three measurements of $\mathrm{sR}_{\mathrm{aw}}$ were performed with each child, and the mean of these was used in the analysis.

\section{Statistical analysis}

Statistical analysis was carried out using SPSS for Windows, version 9.0. $\mathrm{sR}_{\mathrm{aw}}$ measurements followed a log normal distribution, hence were subject to a log e-transformation prior to analysis. Results are thus reported as geometric means (GM). One way analysis of variance (ANOVA) was used to compare differences between the three symptom groups (never wheezed, unconfirmed wheeze, confirmed wheeze).

\section{RESULTS}

Five hundred and twenty five children were followed from birth. Four hundred and seventy five children were invited to a review clinic at 3 years of age (one died, 10 moved out of the area, two were lost to follow up, and 37 were withdrawn by parents). Data were collected on 454 children (fig 1).

One hundred and eighty six $(41.0 \%)$ parents had reported that their child had wheezed, and 130 (28.6\%) of these were confirmed by the primary care physician or a member of the study team. Of the 428 children who attended for review at age 3 years, 153 were unable to complete the lung function assessment (fig 1). Two hundred and seventy five children (64\%) successfully completed pulmonary function assessment; of these, 76 were accompanied by a parent.

There was no significant difference in $s R_{a w}$ between children who had never wheezed $(\mathrm{n}=152$, GM $1.03 \mathrm{kPa} \cdot \mathrm{s}$, 95\% CI 1.00 to 1.06) and those with unconfirmed wheeze $(\mathrm{n}=36$, GM $1.02 \mathrm{kPa} \cdot \mathrm{s}, 95 \%$ CI 0.96 to $1.07 ; \mathrm{p}=1.00)$.
However, $\mathrm{sR}_{\mathrm{aw}}$ was significantly higher in children with confirmed wheeze $(\mathrm{n}=87, \mathrm{GM} 1.17 \mathrm{kPa} \cdot \mathrm{s}, 95 \%$ CI 1.11 to 1.22; $\mathrm{p}<0.001)$ compared to both the children with no history of wheeze or those with unconfirmed wheeze (fig 2).

\section{DISCUSSION}

In our study we have reported that children with parentally reported wheeze which was not confirmed by a physician (unconfirmed wheeze) had identical lung function to those children who had no history of wheeze. However, children with physician confirmed wheeze had significantly poorer lung function compared to either those who had never wheezed or who had unconfirmed wheeze.

\section{Limitations}

Although parents in the study were asked to contact the study team if they heard their child wheeze, no doubt some "wheezy" episodes were not reported to the study team and the children were not seen by their physician at the time, either because the parents did not recognise wheeze or because they failed to act for whatever reason. These children would therefore have been categorised as either "never wheezed" or "unconfirmed wheeze" depending on whether the parent ever reported the episode to the study team. Despite this, there is still a clear difference in $s R_{a w}$ between both the "never wheezed" and "confirmed wheeze" groups, and the "unconfirmed wheeze" and "confirmed wheeze" groups

A further limitation of the study is the large number of physicians who were involved in the assessment of wheeze in the children. It has previously been reported that interobserver agreement on wheeze even among physicians is only moderate-that is, somewhere between chance and total agreement. ${ }^{16}$ Furthermore, the wheeze was not assessed concurrently by physician and parent, limiting the opportunity to distinguish transient wheeze from misinterpretation of wheeze.

\section{Interpretation}

The most likely explanation for our findings is that parents may be confusing other respiratory noises with wheeze. Other studies have previously reported discrepancies between parental and physician reports of wheeze. Cane et al investigated parents' understanding of "wheeze" in children. ${ }^{11}$ A questionnaire administered to parents of children attending a chest clinic revealed that parental understanding of wheeze differed from epidemiological definitions. Furthermore, parents of 139 children admitted to a paediatric A\&E agreed with clinicians on the presence of wheeze in less than half of the cases. The most disagreement occurred over reports of cough and other upper airway noise.

When asked to identify audible breathing noises on video, only $59 \%$ of parents correctly identified wheeze. ${ }^{17}$ In a study of 92 infants with noisy breathing, 59\% of parents initially described their child's symptoms as wheeze, but after being shown video clips of various respiratory sounds including wheeze, ruttle, and stridor, only $36 \%$ still used the term wheeze to describe the symptoms. ${ }^{12}$

An alternative explanation for our results is that those children with only unconfirmed wheeze had very mild or extremely transient symptoms of wheeze which were not present when seen by the physician. These very mild symptoms appeared not to have caused any significant effect on specific airway resistance when measured at age 3 years. However, it is unlikely that symptoms would have completely disappeared within the hours from onset and the time of clinical examination, when symptoms caused sufficient parental concern for them to contact the study team in the first instance. 


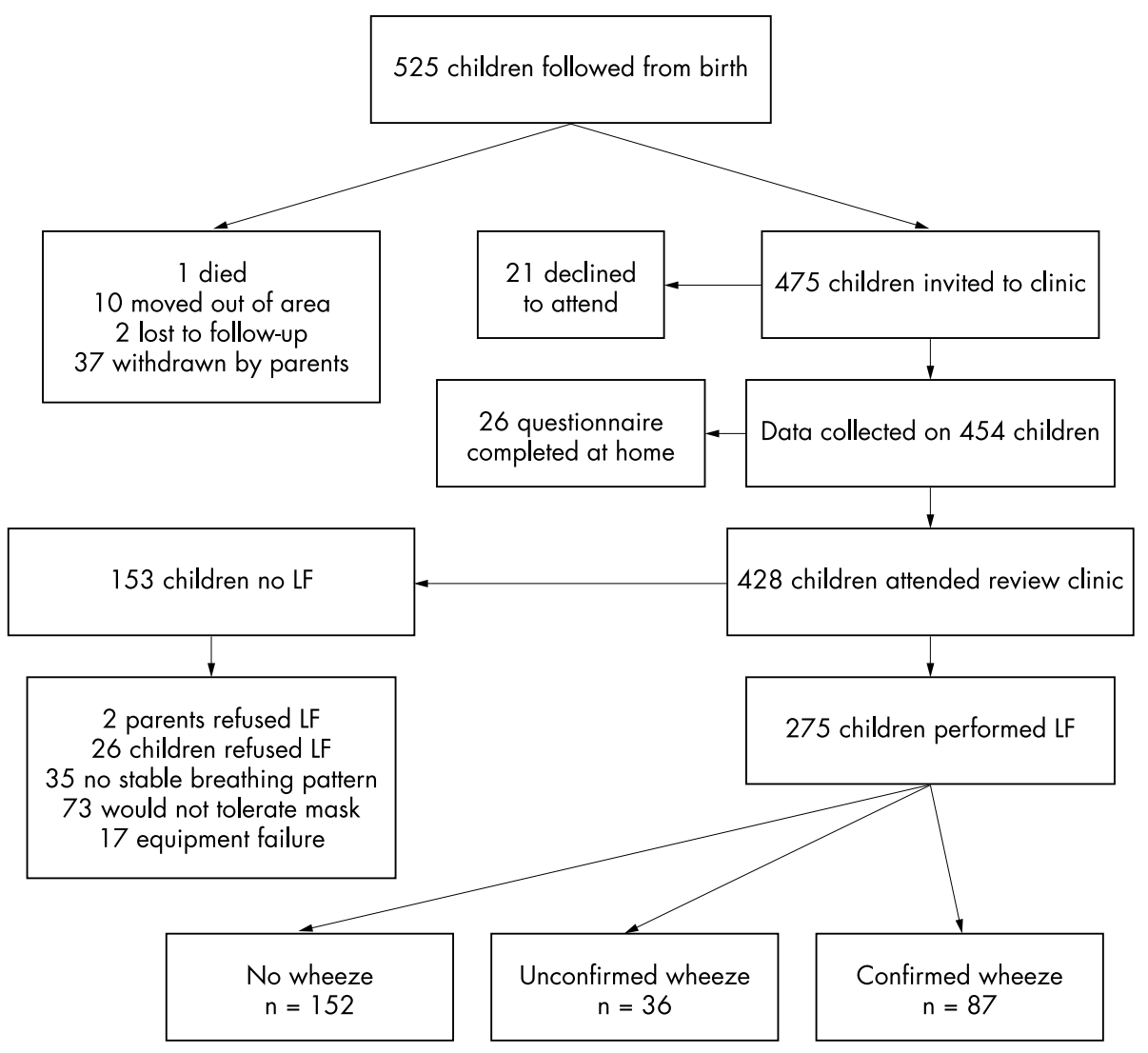

Figure 1 Study profile.

\section{Conclusions}

This study adds further weight to the argument that many parents have little understanding of what physicians mean by the term "wheeze". Clearly parental perception of "wheeze" is very variable. The study shows the importance of using objective measures wherever possible in the diagnosis and also the follow up of children with reported wheeze. Epidemiological studies must be wary when interpreting questionnaire data of parentally reported symptoms and disease, as up to $30 \%$ of parentally reported wheeze was probably not a wheeze in the first place. There are also important implications for the recruitment of children into

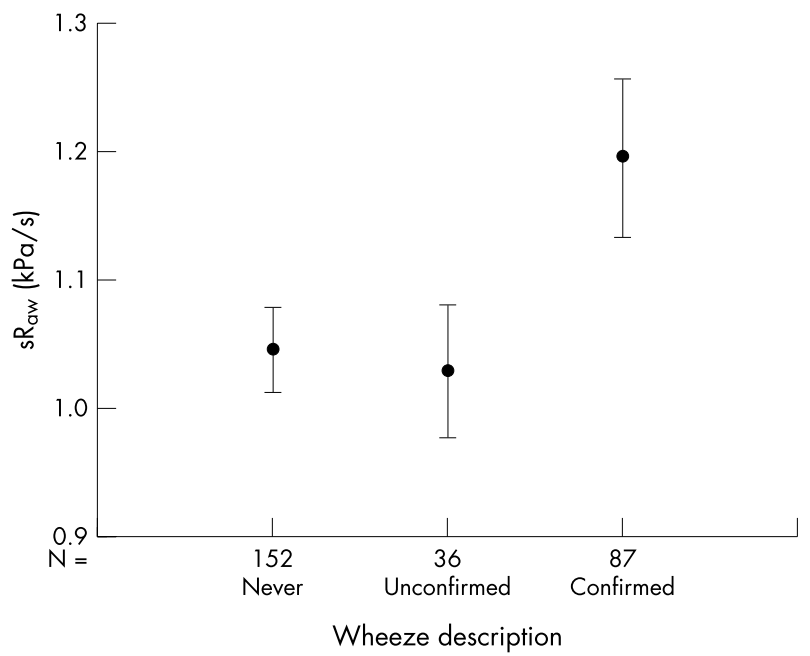

Figure 2 Comparison of $s \mathrm{R}_{\mathrm{aw}}$ in children with no history of wheeze, and unconfirmed and confirmed wheeze. studies on the safety and efficacy of pharmaceutical interventions, which should be limited to those children with physician confirmed wheeze only.

\section{ACKNOWLEDGEMENTS}

This study was partly funded by The National Asthma Campaign and GlaxoSmithKline. The authors would like to thank all the parents and children who took part and all members of the ${ }^{\mathrm{NAC}}$ MAAS Study group.

\section{Authors' affiliations}

L Lowe, C S Murray, L Martin, J Deas, E Cashin, G Poletti, A Simpson,

A Woodcock, A Custovic, North West Lung Research Centre,

Wythenshawe Hospital, Southmoor Road, Manchester M23 9LT, UK

\section{REFERENCES}

1 Ninan TK, Russell G. Respiratory symptoms and atopy in Aberdeen schoolchildren: evidence from two surveys 25 years apart. BMJ 1992;304:873-5

2 Peat JK, van den Berg RH, Green WF, et al. Changing prevalence of asthma in Australian children. BMJ 1994;308:1591-6.

3 Anderson HR, Butland BK, Strachan DP. Trends in prevalence and severity of childhood asthma. BMJ 1994;308:1600-4.

4 Eigen $H$, Bieler $H$, Grant $D$, et al. Spirometric pulmonary function in healthy preschool children. Am J Respir Crit Care Med 2001;163(3 pt 1):619-23.

5 Vilozni D, Barker $M$, Jellouschek $H$, et al. An interactive computer-animated system (Spirogame) facilitates spirometry in preschool children. Am J Respir Crit Care Med 2001;164:2200-5.

6 Crenesse D, Berlioz M, Bourrier T, et al. Spirometry in children aged 3 to 5 years: reliability of forced expiratory maneuvers. Pediatr Pulmonol 2001;32:56-61.

7 Nystad W, Samuelsen SO, Nafstad P, et al. Feasibility of measuring lung function in preschool children. Thorax 2002;57:1021-7.

8 Bisgaard $\mathrm{H}$, Klug B. Lung function measurement in awake young children. Eur Respir J 1995;8:2067-75

9 Klug B, Bisgaard H. Measurement of specific airway resistance by plethysmography in young children accompanied by an adult. Eur Respir J 1997; 10:1599-605.

10 Lowe L, Murray CS, Custovic A, et al. Specific airway resistance in 3-year-old children: a prospective cohort study. Lancet 2002;359:1904-8. 
11 Cane RS, Ranganathan SC, McKenzie SA. What do parents of wheezy children understand by "wheeze"? Arch Dis Child 2000;82:327-32.

12 Elphick HE, Sherlock PG, Foxall EJ, et al. Survey of respiratory sounds in infants. Arch Dis Child 2001;84:35-9.

13 Custovic A, Simpson BM, Simpson A, et al. Manchester Asthma and Allergy Study: low-allergen environment can be achieved and maintained during pregnancy and in early life. J Allergy Clin Immunol 2000;105(2 pt 1):252-8.
14 Custovic A, Simpson BM, Murray CS, et al. The National Asthma Campaign Manchester Asthma and Allergy Study. Pediatr Allergy Immunol 2002; 13(suppl 15):32-7.

15 Dab I, Alexander F. On the advantages of specific airway resistance. Paediatr Res 1978;12:878-81.

16 Pasterkamp H, Wiebecke W, Fenton R. Subjective assessment vs computer analysis of wheezing in asthma. Chest 1987;91:376-81.

17 Cane RS, McKenzie SA. Parents' interpretations of children's respiratory symptoms on video. Arch Dis Child 2001;84:31-4.

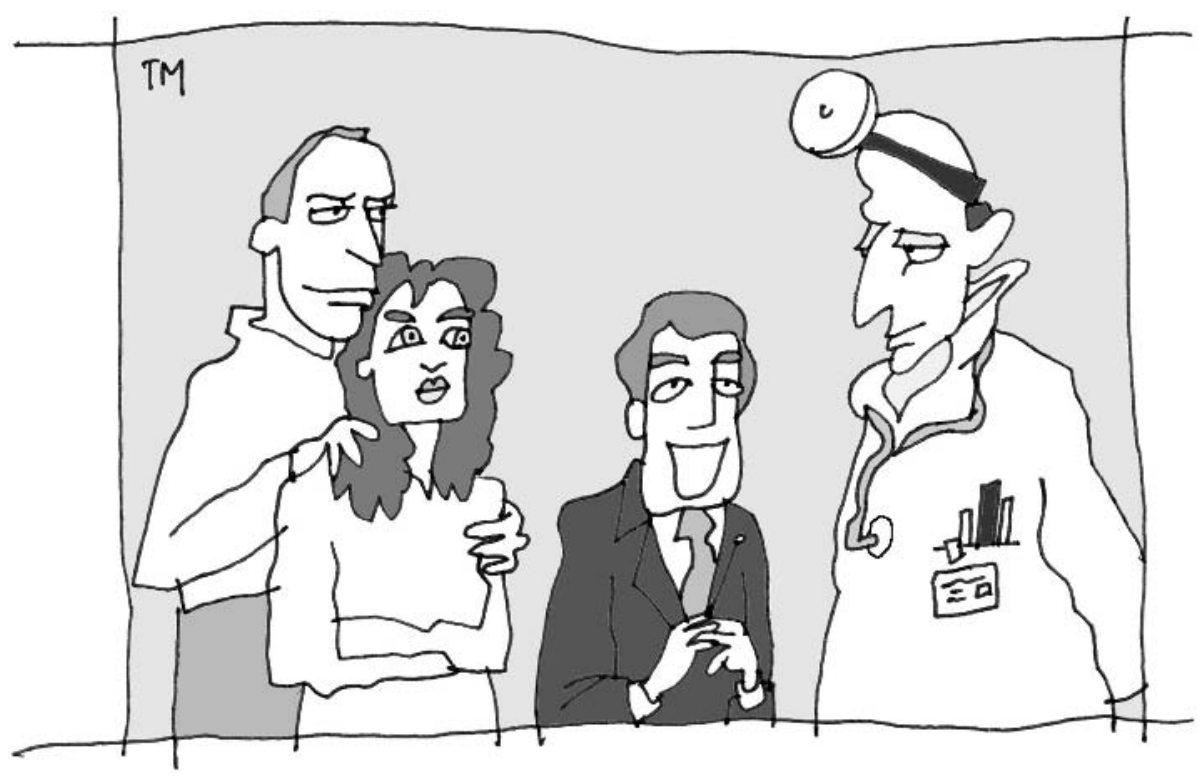

